\title{
Thermal properties of neryl long-chain esters obtained under microwave irradiation
}

\author{
Marta Worzakowska
}

Received: 17 November 2014 / Accepted: 23 January 2015/Published online: 19 February 2015

(C) The Author(s) 2015. This article is published with open access at Springerlink.com

\begin{abstract}
Thermal properties of novel, neryl long-chain esters obtained through the esterification process of nerol, different chain lengths acidic components such as succinic anhydride, glutaric anhydride, adipic acid or sebacic acid and diol components such as ethylene glycol or diethylene glycol in solvent-free conditions under microwave irradiation were studied by TG/FTIR-coupled method. The studies confirmed that the use of microwave irradiation allowed obtaining flavor esters in absolutely shorter reaction time (only minutes) with high purity and yield compared to conventional method. The prepared novel, neryl long-chain esters were high thermal stable compounds and decomposed at three stages under air conditions including the breaking of ester bonds, oxidation and decarboxylation processes of formed intermediate products in a gaseous phase and thus the emission of various gaseous products. It was indicated on the same, complex and parallel decomposition mechanism under oxidative conditions for the present and previously studied long-chain esters of primary order terpene alcohols showing it independence on the type of alcohol used for their synthesis.
\end{abstract}

Keywords Nerol · Esters - Microwave irradiation · Thermal degradation · TG/FTIR-coupled method

\section{Introduction}

Microwave irradiation is a technique widely used to promote and accelerate many chemical reactions such as

M. Worzakowska ( $\square)$

Department of Polymer Chemistry, Faculty of Chemistry, Maria

Curie-Skłodowska University, Gliniana 33 Street,

20-614 Lublin, Poland

e-mail: marta.worzakowska@ poczta.umcs.lublin.pl cycloaddition, addition, elimination and substitution reactions [1-3]. This technique is commonly applied in the synthesis of many organic and polymer compounds [4-6] due to its simplicity, efficiency and swiftly. The application of microwave irradiation allows reducing reaction times from hours to minutes or seconds, increasing reaction yield and the purity of the final product as compared to the conventional methods [7-9]. In addition, the solvent-free, microwave-assisted reactions are considered to be an ecofriendly approach [2, 10]. Due to this, microwave-assisted processes have become a great attention in recent years. The one of the organic reactions which can be successfully performed with the use of microwave is the formation of ester compounds. Esters are among the most important industrial products which have many commercial applications. They are utilized as plasticizers, lubricants, as a component of perfumes, cosmetics, pharmaceuticals, food preservatives or intermediate compounds for the synthesis of drugs, fine chemicals or others [11-16]. The solventfree, microwave-assisted synthesis of many types of ester compounds during direct esterification or transesterification methods have been reported [17-24]. However, little information regarding the microwave-assisted synthesis of flavor esters derivatives of monoterpene compounds such as geraniol, nerol or citronellol have been described. Traditionally, chemically those esters are prepared in catalyzed esterification process of monoterpene alcohols with acid anhydrides or acid chlorides using large excess of terpene alcohol and often toxic solvents [13, 25]. Recently, we have proposed the method of the preparation of geranyl, neryl and citronellyl diesters [26-28] and long-chain esters of geraniol [29, 30] using butylstannoic acid as a catalyst under conventional conditions. The use of such catalyst allowed reducing the formation of by-products, using of stoichiometric amount of reagents and significantly 
increasing the yields of pure product which consequently reduced the production cost of flavor esters for cosmetic, laundry and perfume applications. However, this reaction also has some drawbacks. The main of them is long synthesis time and consequently high energy consumption. In order to improve this method of synthesis of flavor esters, microwave irradiation seems to be a promising way.

In the present study, thermal properties of new, flavor neryl long-chain esters obtained under free solvent microwave irradiation were studied. The microwave-assisted catalyzed esterification reaction was performed using a stoichiometric ratio of reagents such as terpene alcohol: nerol, different chain lengths acidic components such as succinic anhydride, glutaric anhydride, adipic acid or sebacic acid and diol components such as ethylene glycol or diethylene glycol in solvent-free conditions. To compare the results, those esters were also obtained under conventional method described in Refs. [29, 30]. Their thermal properties and the type of emitted gaseous products under oxidative conditions were studied by TG/FTIR-coupled method, and the obtained results were compared to the previously studied $[29,30]$.

\section{Experimental}

\section{Materials}

Nerol $(97 \%)$ and glutaric anhydride $(95 \%)$ were from Fluka. Ethylene glycol, diethylene glycol (99\%), succinic anhydride (99\%), adipic acid (99\%) and sebacic acid (98\%) were delivered by Merck. The catalyst (butylstannoic acid) was purchased from Arkema Inc., USA.

\section{Synthesis}

The long-chain esters of nerol were obtained through conventional esterification method according to Refs. [29, 30] and microwave-assisted synthesis using butylstannoic acid as a catalyst. In a typical experiment, the reagents were used at the molar ratio of 2:2:1 (nerol/anhydride acid/diol). The reaction mixture was stirred at $140{ }^{\circ} \mathrm{C}$ in an oil bath under reduced pressure (conventional conditions) or irradiated using RM-800 multimode microwave reactor (Plazmatronika, Poland) for appropriate reaction time.

After the microwave reaction was finished, the raw product was cooled, dissolved in ethyl ether and dried over magnesium sulfate in order to remove water forming during this process. Then, the solvent was removed under reduced pressure and the product was analyzed.
To estimate the degree of conversion of hydroxyl and carboxyl groups (in order to determine the conversion of substrates), the acid number and hydroxyl number of the product were marked. Acid number was evaluated by titration of the sample dissolved in acetone against $0.1 \mathrm{~N}$ solution of $\mathrm{KOH}$. Phenolphthalein was used as an indicator. Hydroxyl number was evaluated by acetylation method. The sample was titrated by $0.5 \mathrm{~N}$ solution of $\mathrm{KOH}$ in the presence of phenolphthalein.

The corresponding abbreviations for obtained esters were used: Ner-BB-GE (ester of nerol-succinic anhydrideethylene glycol), Ner-BG-GE (ester of nerol-glutaric anhydride-ethylene glycol), Ner-AA-GE (ester of neroladipic acid-ethylene glycol), Ner-BB-DEG (ester of nerolsuccinic anhydride-diethylene glycol), Ner-BG-DEG (ester of nerol-glutaric anhydride-diethylene glycol), Ner-AADEG (ester of nerol-adipic acid-diethylene glycol) and Ner-SA-DEG (ester of nerol-adipic acid-diethylene glycol), respectively.

\section{Analytical methods}

ATR-FTIR spectra were recorded using a spectrometer Brucker TENSOR 27, equipped with diamond crystal (Germany). The spectra were recorded in the spectral range of $600-4,000 \mathrm{~cm}^{-1}$. The resolution of each spectrum was $4 \mathrm{~cm}^{-1}$.

${ }^{1} \mathrm{H}-\mathrm{NMR}$ spectra were obtained on an NMR spectrometer Brucker-Avance 300 MSL (Germany) working at $300 \mathrm{MHz}$. The deuterated chloroform was applied as the solvent. The tetramethylsilane was used as an internal reference.

The viscosity of the product was determined by Brookfield DV-III rheometer (Germany) at $25{ }^{\circ} \mathrm{C}$.

Density was measured at $23{ }^{\circ} \mathrm{C}$ with the use of Gay/ Lussac pycnometer.

Refractive index was qualified at $23{ }^{\circ} \mathrm{C}$ by Carl Zeis Jena refractometer.

Thermal analysis was carried out on a STA 449 Jupiter F1, Netzsch (Germany). The samples were heated from $40{ }^{\circ} \mathrm{C}$ to $640{ }^{\circ} \mathrm{C}$ in $\mathrm{Al}_{2} \mathrm{O}_{3}$ crucibles under oxidative (synthetic air) atmosphere with flow rate $40 \mathrm{~mL} \mathrm{~min}{ }^{-1}$. The heating rate was $10{ }^{\circ} \mathrm{C} \mathrm{min}-1$. From the obtained TG curves, the initial decomposition temperature (IDT) which corresponds to the $5 \%$ of mass loss and mass loss $\left(\mathrm{W}_{\text {loss }}\right)$ for each step were evaluated. Based on DTG, peak maximum temperature $\left(T_{\max }\right)$ was determined. The type of the gaseous products emitted in each step of decomposition was evaluated with the use of FTIR Brucker spectrometer (Germany) coupling online to STA instrument. The FTIR 
spectrometer cell and the transfer Teflon line were heated to $200{ }^{\circ} \mathrm{C}$ in order to avoid the condensation process of gaseous products. The FTIR spectra were gathered from 600 to $4,000 \mathrm{~cm}^{-1}$ at a resolution of $4 \mathrm{~cm}^{-1}$, every $10{ }^{\circ} \mathrm{C}$.

\section{Results and discussion}

The novel, long-chain esters of nerol were obtained under conventional conditions and microwave-assisted synthesis in the absence of solvent and under atmospheric pressure. The esters were prepared using nerol as terpene alcohol, two chosen aliphatic diols such as ethylene glycol and diethylene glycol and different aliphatic, chain length acid anhydrides such as succinic anhydride and glutaric anhydride and dicarboxylic acids such as adipic acid and sebacic acid. Tables 1 and 2 show the results obtained during the traditional esterification process and microwaveassisted process. There are some easy to seen differences when one compare the conventional and microwaveassisted process. As it is clearly visible, to obtain high conversion of hydroxyl and carboxyl groups, the conventional process requires longer time (from 24 to $53 \mathrm{~h}$

Table 1 The conversion of hydroxyl and carboxyl groups and the reaction time of esters obtained by conventional method

\begin{tabular}{llll}
\hline Compound & $\begin{array}{l}\text { Reaction } \\
\text { time/h }\end{array}$ & $\begin{array}{l}\text { Conversion } \\
\text { of hydroxyl } \\
\text { groups/\% }\end{array}$ & $\begin{array}{l}\text { Conversion of } \\
\text { carboxyl } \\
\text { groups/\% }\end{array}$ \\
\hline Ner-BB-GE & 24 & 96.5 & 95.8 \\
Ner-BG-GE & 28 & 96.4 & 95.6 \\
Ner-AA-GE & 35 & 97.2 & 95.7 \\
Ner-SA-GE & 47 & 97.0 & 96.0 \\
Ner-BB-DEG & 30 & 96.3 & 95.4 \\
Ner-BG-DEG & 35 & 96.8 & 95.7 \\
Ner-AA-DEG & 42 & 96.9 & 95.3 \\
Ner-SA-DEG & 53 & 97.2 & 95.5 \\
\hline
\end{tabular}

Table 2 The conversion of hydroxyl and carboxyl groups and the reaction time of esters obtained by microwave method

\begin{tabular}{lcll}
\hline Compound & $\begin{array}{l}\text { Reaction } \\
\text { time/min }\end{array}$ & $\begin{array}{l}\text { Conversion } \\
\text { of hydroxyl groups/\% }\end{array}$ & $\begin{array}{l}\text { Conversion } \\
\text { of carboxyl } \\
\text { groups/\% }\end{array}$ \\
\hline Ner-BB-GE & 7 & 97.2 & 96.2 \\
Ner-BG-GE & 8 & 97.0 & 96.1 \\
Ner-AA-GE & 10 & 97.5 & 96.5 \\
Ner-SA-GE & 12 & 97.8 & 96.0 \\
Ner-BB-DEG & 9 & 96.7 & 95.8 \\
Ner-BG-DEG & 11 & 96.9 & 95.9 \\
Ner-AA-DEG & 13 & 97.3 & 96.4 \\
Ner-SA-DEG & 15 & 97.0 & 95.9 \\
\hline
\end{tabular}

depending on the ester structure) than microwave-assisted process. In this case, only few minutes is needed in order to prepare the final product with high purity and yield. There are many factors which influences on the rate and yield of the microwave-assisted synthesis of esters, i.e., polarity of reagents, catalyst, microwave power, reaction time or reaction temperature. One of the most important is the polarity of reagents. Generally, when a molecule is irradiated with microwaves, it will attempt to align itself with electric field by rotation [2, 7-9]. The electric energy is absorbed by the molecule when the frequency of molecular rotation is similar to the frequency of microwave irradiation. In such situation, the molecule will continually be able to align and realign itself with the oscillating field. Generally, polar molecules absorb microwave energy more rapidly than less polar or compounds with no dipole moment [2, 7-9]. In those studies, all reagents used for the synthesis of long-chain neryl esters are polar compounds. However, they differ in their polarities. Generally, the O-H bond in acids is more polar than $\mathrm{O}-\mathrm{H}$ bond in alcohols due to the electron withdrawing effect of carbonyl group in $\mathrm{O}-$ $\mathrm{H}$. In addition, alcohol and acid molecules with shorter carbon chain length are more polar and more easily rotated and rerotated under microwave irradiation producing more heat $[2,7-9]$ than alcohol and acid molecules with longer carbon chain length. Also, the polarity of reagents is increased as a number of polar groups in the molecule increased, so diols are more polar than terpene alcohol. Due to those, the differences in reaction times which are required to obtain high conversions of substrates are visible. The shorter carbon chain esters are prepared under shorter reaction time than longer carbon chain esters which is connected with the higher polarity of shorter carbon chain acids and diols. Also, the esters where ethylene glycol is used for the synthesis are obtained during shorter reaction time than esters prepared in the presence of diethylene glycol which is directly connected with a bit higher ethylene glycol polarity compared to diethylene glycol polarity.

The structure of esters was confirmed by ATR-FTIR and ${ }^{1}$ HNMR spectroscopic methods. The most characteristic ATR-FTIR signals for those esters compounds are presented in Fig. 1. As it is visible, those spectra show the absence of the signals characteristic for the stretching vibrations of $-\mathrm{OH}$ and $-\mathrm{COOH}$ (the area of wavenumber above $3,400 \mathrm{~cm}^{-1}$ ) present in the structure of substrates as well as the stretching vibrations of $-\mathrm{OH}$ groups from water [31]. It fully confirmed that the microwave-assisted reaction allows obtaining the desirable, fine final product. Also, the signals regarding to the all protons in the structure of prepared esters are visible, Fig. 2. The protons attached to carbon-carbon double bonds are visible as two signals at 5.10 and $5.35 \mathrm{ppm}(\mathrm{e}, \mathrm{f})$. The protons in $-\mathrm{CH}_{2}-\mathrm{O}-$ groups 

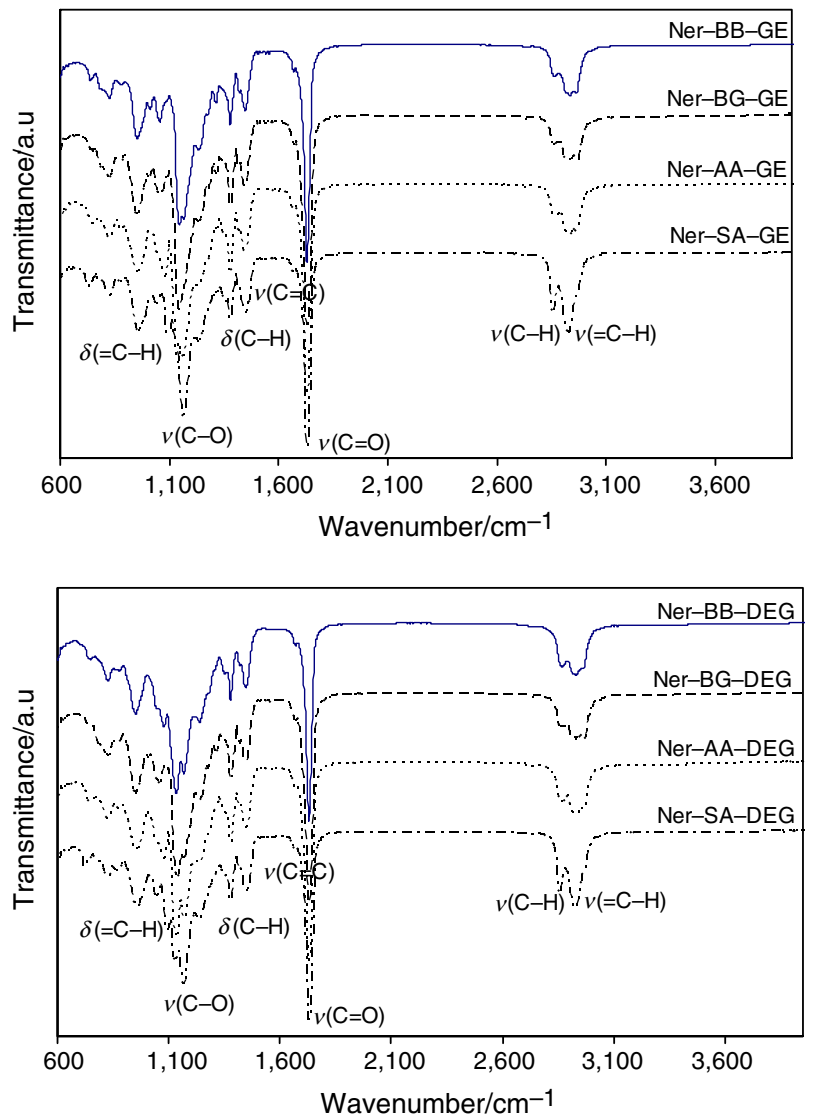

Fig. 1 ATR-FTIR spectra of obtained esters

in ester compounds are appeared at $4.10 \mathrm{ppm}(\mathrm{g})$ and $4.60 \mathrm{ppm}$ (d). The presence of those protons confirmed the formation of ester compounds having two different ester groups in their structure. The protons' characteristic for the rest $-\mathrm{CH}_{2}-$ and $-\mathrm{CH}_{3}$ groups is indicated in the range below 3.0 ppm (a, a', b, c).

The obtained long-chain esters of nerol are compounds with fresh, floral odor. Their physical properties are presented in Table 3. It is clearly visible that the properties of obtained esters are fully related to the structures of diols and acids used. The esters of nerol which were synthesized with the use of ethylene glycol are characterized by lower values of viscosity, density and refractive index compared to those obtained with the use of diethylene glycol. In addition, the viscosity, density and refractive index of esters having longer aliphatic chain lengths in their structure have higher values than for esters having shorter, aliphatic chain lengths in the structure.

The prepared esters are high thermal stable compounds in air. The initial decomposition temperature (IDT) is higher than $200{ }^{\circ} \mathrm{C}$ for neryl esters prepared using ethylene glycol and higher than $190{ }^{\circ} \mathrm{C}$ for neryl esters obtained in the presence of diethylene glycol, Table 4 . The TG/DTG curves are presented in Fig. 3. The decomposition of esters under air conditions happens at three main stages. The first and second decomposition stages were not well separated. The first decomposition stage was visible up to temperatures c.a. $290^{\circ} \mathrm{C}$ for Ner-BB-GE and Ner-BB-DEG and up to temperatures above $300{ }^{\circ} \mathrm{C}$ for the rest of esters. The mass loss was significant in this stage. It was from 63.3 to $52.5 \%$ for neryl esters prepared in the presence of ethylene glycol and from 63.5 to $45.3 \%$ for neryl esters prepared with the use of diethylene glycol. In addition, the decreasing of mass loss as molecular mass of the esters increases was indicated in this decomposition stage, which was directly connected with the formation, evaporation or emission of different amounts of decomposition products dependent on the ester structure. The second decomposition stage was spread from temperatures $290-300{ }^{\circ} \mathrm{C}$ to $420{ }^{\circ} \mathrm{C}$ with $T_{\max 2}$ above $320{ }^{\circ} \mathrm{C}$. The mass loss was from 29.3 to $36.6 \%$ for ethylene glycol-based esters and from 29.2 to $39.9 \%$ for diethylene glycol-based esters. In addition, the mass loss in this stage increased as the molecular mass of esters increased. The third, only one fully separated decomposition stage was observed at higher temperatures (above $420{ }^{\circ} \mathrm{C}$ ) with the lowest mass loss from 7.4 to $10.9 \%$ for ethylene glycol-based esters and from 7.3 to $14.8 \%$ for diethylene glycol-based esters. Similarly, in this stage of decomposition as the molecular mass of esters increased, the mass loss also increased.

The FTIR spectra of the emitted gaseous products during esters decomposition are presented in Figs. 4 and 5, respectively. The most characteristic absorption signals of the gaseous products emitted in each stage during decomposition of studied esters are marked in Fig. 5. At $T_{\max 1}$, mainly the formation of alkene, aldehyde, alcohol fragments, water and carbon dioxide are observed. It is the result of the $\beta$-elimination process of esters, partial oxidation and decarboxylation of formed intermediate products in a gaseous phase [32-34]. As the result of those processes, the appearance of the absorption bands' characteristic for alkenes [signals at 821 and $987 \mathrm{~cm}^{-1}(\delta=\mathrm{C}-\mathrm{H})$, at $1,600-1,620 \mathrm{~cm}^{-1}(v \mathrm{C}=\mathrm{C})$ and at $3,085 \mathrm{~cm}^{-1}(v=\mathrm{C}-\mathrm{H})$, for aldehydes signals at $1,713-1,732 \mathrm{~cm}^{-1}$ and at $\left.1,155-1,245 \mathrm{~cm}^{-1} \quad(v \mathrm{C}-\mathrm{O})\right]$ for alcohol (signals at $1,085-1,185 \mathrm{~cm}^{-1}$ ( $v \mathrm{C}-\mathrm{O}$ in hydroxyl compounds) and at $3,570-3,730 \mathrm{~cm}^{-1}(\mathrm{v}-\mathrm{OH})$ was observed. Also, in this decomposition stage, the evaporation of water vapor $\left(3,600-3,740 \mathrm{~cm}^{-1}\right)[26-30,35,36]$ and emission of carbon dioxide $\left(670 \mathrm{~cm}^{-1}\right.$ and $\left.2,330-2,365 \mathrm{~cm}^{-1}\right)[26-30,34,37]$ are indicated. At $T_{\max 2}$, besides the products observed at $T_{\max 1}$, the evaporation of an acid anhydride (signals at 900 , $1,050,1,811$ and $1,870 \mathrm{~cm}^{-1}$ responsible for $v \mathrm{C}-\mathrm{O}$ and $\mathrm{C}=\mathrm{O}$ groups) is clearly indicated for neryl esters obtained using shorter acid chain length (succinic anhydride and glutaric anhydride) [26-30]. For neryl esters based on adipic acid and sebacic acid, the evaporation of an acid anhydride 
Fig. $2{ }^{1}$ HNMR spectra of obtained esters

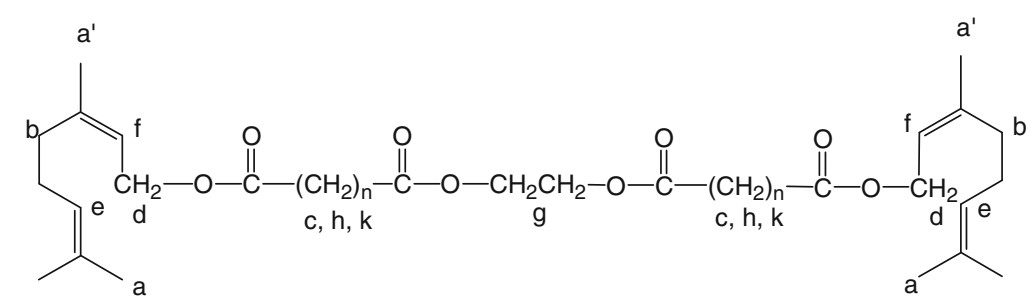
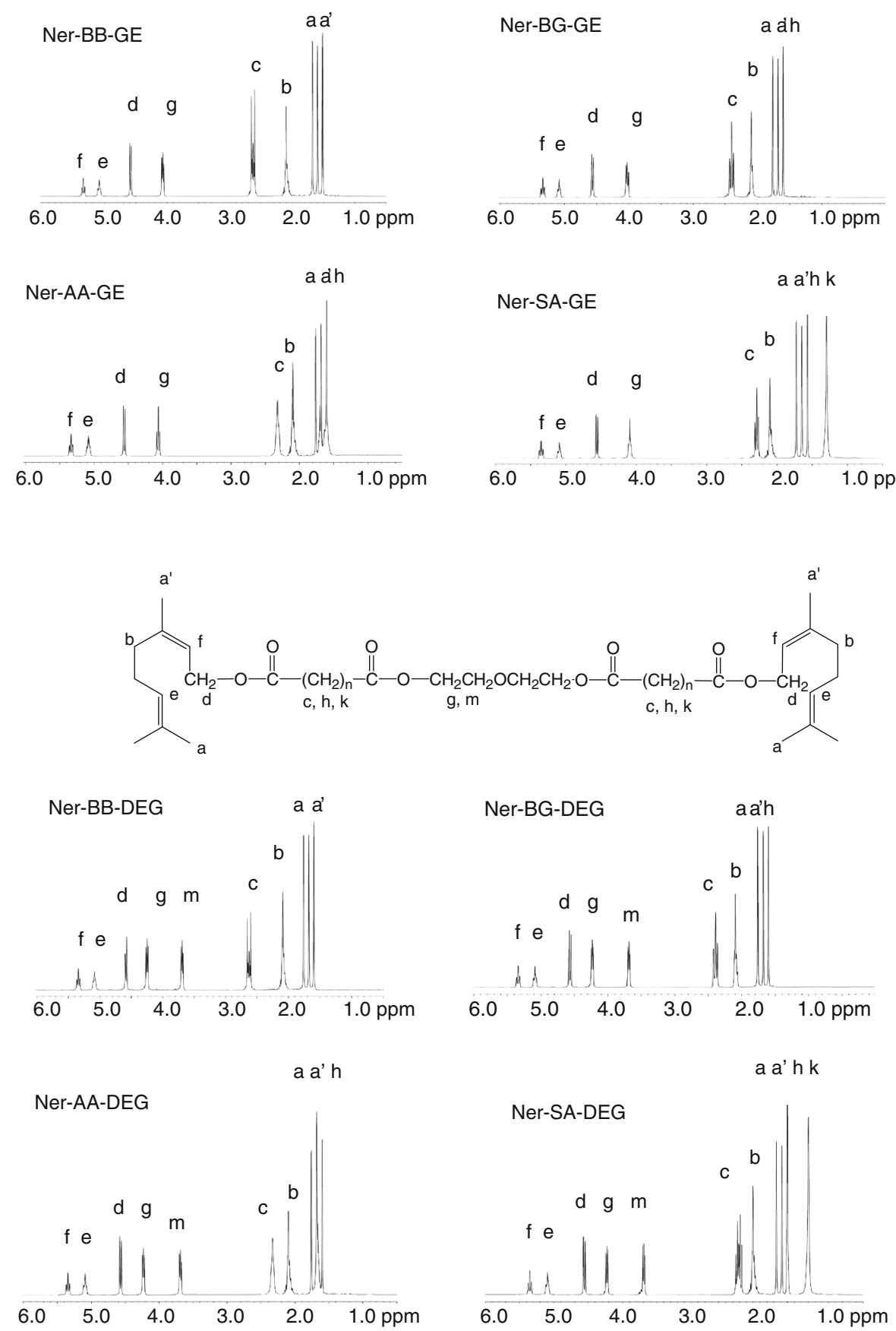

is not observed. It is connected with the stability of formed cyclic anhydrides. The 7 and 11 membered anhydrides due to their low stability, decomposes in air losing $\mathrm{CO}_{2}$. In this reaction, as a main decomposition compounds, cyclic ketones are formed [26-30]. The formation of those compounds during decomposition of neryl esters based on adipic 
Table 3 Physical properties of esters

\begin{tabular}{lcll}
\hline Compound & Viscosity/mPas & Density/g cm ${ }^{-1}$ & Refractive index \\
\hline Ner-BB-GE & 74.8 & 1.0485 & 1.4820 \\
Ner-BG-GE & 87.5 & 1.0495 & 1.4845 \\
Ner-AA-GE & 126.8 & 1.0560 & 1.4860 \\
Ner-SA-GE & 153.4 & 1.0575 & 1.4875 \\
Ner-BB-DEG & 90.0 & 1.0795 & 1.4825 \\
Ner-BG-DEG & 108.6 & 1.0825 & 1.4845 \\
Ner-AA-DEG & 152.4 & 1.0890 & 1.4880 \\
Ner-SA-DEG & 193.7 & 1.0985 & 1.4895 \\
\hline
\end{tabular}

and sebacic acids was confirmed by the presence of absorption signals at $1,768-1,790 \mathrm{~cm}^{-1}(\vee \mathrm{C}=\mathrm{O})$ and at $1,008-1,178 \mathrm{~cm}^{-1}$ ( $\left.\vee \mathrm{C}-\mathrm{O}\right)$ on FTIR spectra [31].
In a raw, at $T_{\max 3}$, mainly the emission of water and carbon dioxide is observed. However, also at $T_{\max 3}$, the presence of an acid anhydride, for neryl esters prepared in the presence of succinic and glutaric anhydrides is observed. It indicated that an acid anhydride evaporates slowly in a wide range of temperatures. For higher chain length esters, no other decomposition products than $\mathrm{H}_{2} \mathrm{O}$ and $\mathrm{CO}_{2}$ was indicated. The obtained results were in accordance with the previously studied [29, 30]. It is worth to noting that the decomposition mechanism of long-chain esters of nerol was complex and parallel. The decomposition of studied esters proceed via the same path as for previously studied esters and was independent on the terpene alcohol used for the synthesis of esters $[29,30]$.

Table 4 TG-DTG data of obtained esters

\begin{tabular}{|c|c|c|c|c|c|c|c|}
\hline compound & $\mathrm{IDT} /{ }^{\circ} \mathrm{C}$ & $T_{\max 1} /{ }^{\circ} \mathrm{C}$ & $\mathrm{W}_{\text {loss } 1} 1 \%$ & $T_{\max 2} /{ }^{\circ} \mathrm{C}$ & $\mathrm{W}_{\text {loss } 2} / \%$ & $T_{\max 3} /{ }^{\circ} \mathrm{C}$ & $\mathrm{W}_{\text {loss } 3} / \%$ \\
\hline Ner-BB-GE & 203 & 251 & 63.3 & 347 & 29.3 & 479 & 7.4 \\
\hline Ner-BG-GE & 204 & 260 & 59.2 & 357 & 32.3 & 486 & 8.5 \\
\hline Ner-AA-GE & 210 & 277 & 55.2 & 358 & 35.0 & 478 & 9.8 \\
\hline Ner-SA-GE & 230 & 280 & 52.5 & 365 & 36.6 & 480 & 10.9 \\
\hline Ner-BB-DEG & 193 & 244 & 63.5 & 331 & 29.2 & 471 & 7.3 \\
\hline Ner-BG-DEG & 193 & 245 & 54.9 & 340 & 37.1 & 482 & 8.0 \\
\hline Ner-AA-DEG & 195 & 268 & 52.8 & 323 & 37.8 & 480 & 9.4 \\
\hline Ner-SA-DEG & 211 & 273 & 45.3 & 376 & 39.9 & 513 & 14.8 \\
\hline
\end{tabular}
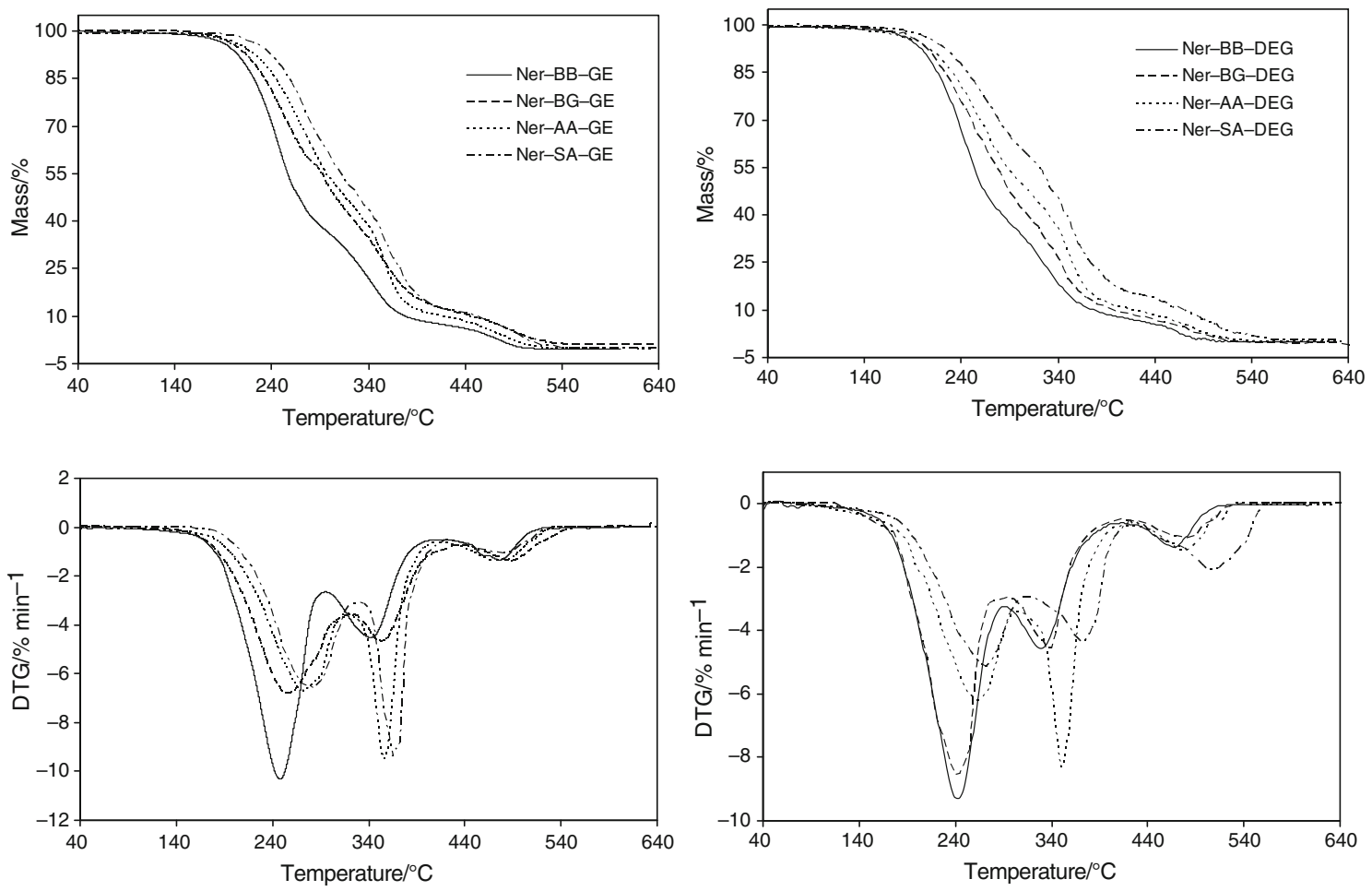

Fig. 3 TG/DTG curves of obtained esters 
Fig. 4 3D FTIR spectra of neryl esters prepared in the presence of ethylene glycol

Fig. 5 3D FTIR spectra of neryl esters prepared in the presence of diethylene glycol

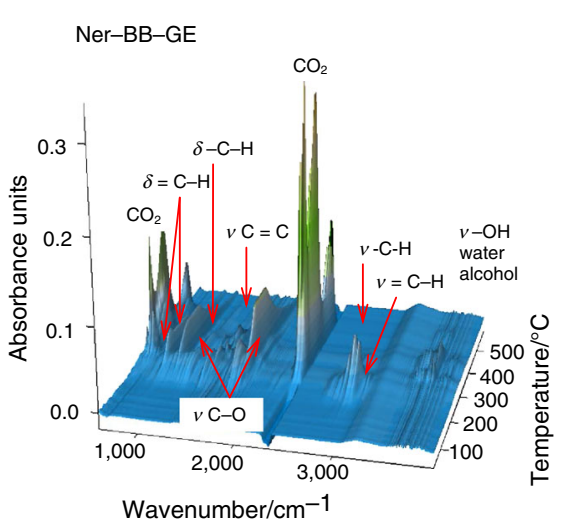

Ner-AA-GE
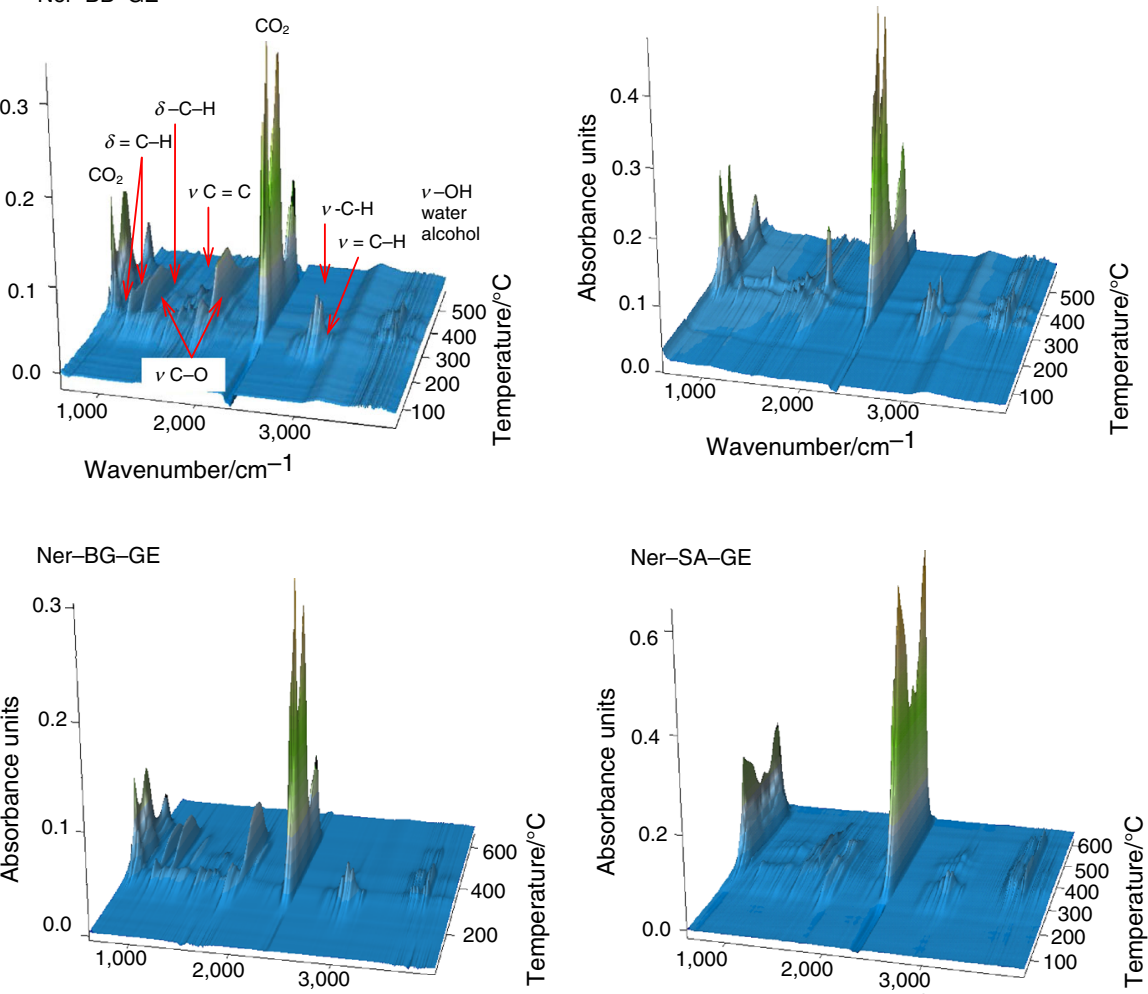

Wavenumber $/ \mathrm{cm}^{-1}$
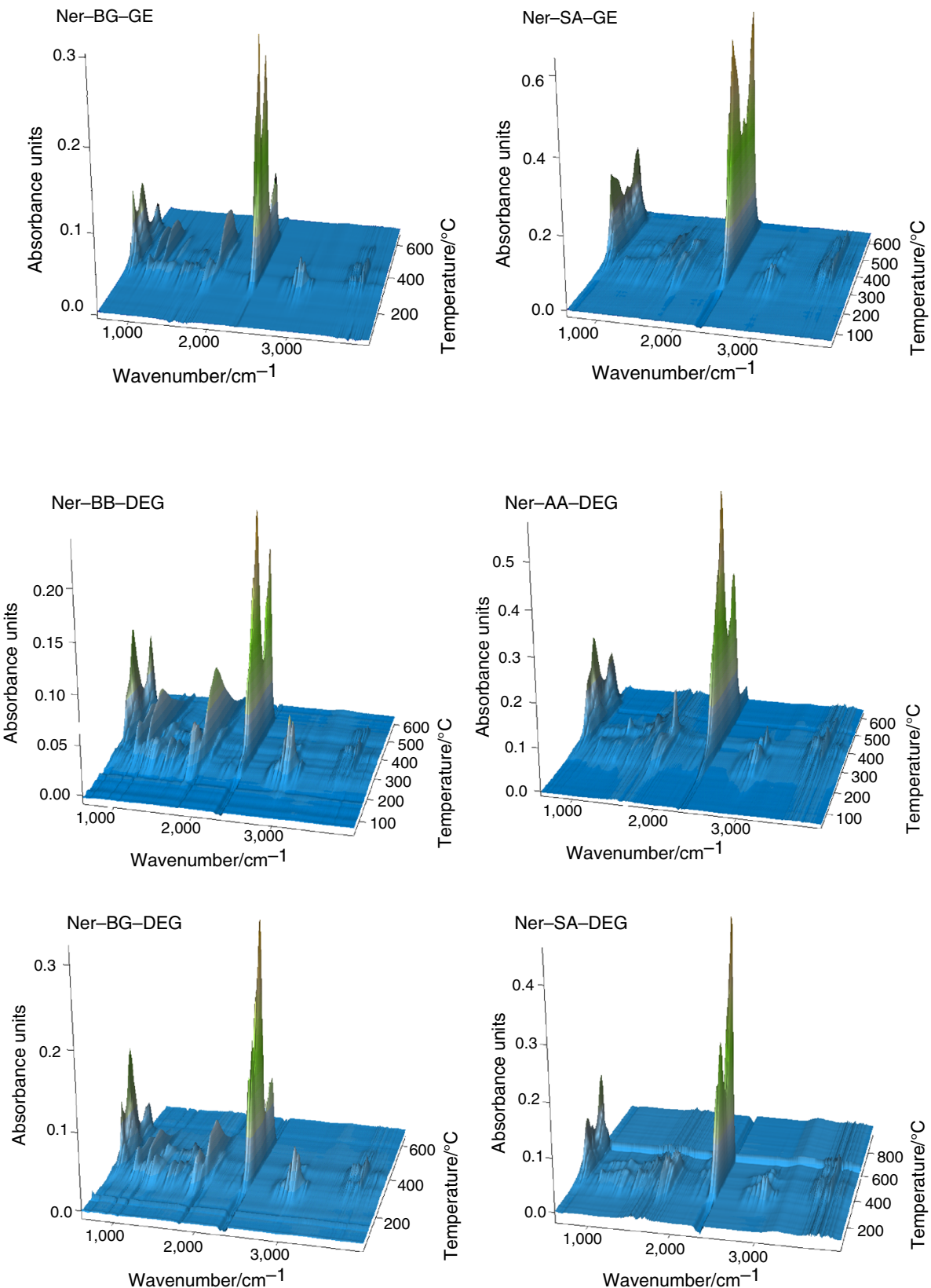


\section{Conclusions}

Those studies confirmed that the use of microwave irradiation allowed obtaining high thermal stable, novel flavor esters in absolutely shorter reaction time with high purity and yield when compared to conventional method. The decomposition process of prepared esters happened in three main stages under oxidative conditions. The breaking of ester bonds, oxidation and decarboxylation processes of formed intermediate products in a gaseous phase and thus the emission of various gaseous products were confirmed based on TG/FTIR analysis. The obtained results were indicated on the complex, parallel and the same decomposition mechanism of studied neryl long-chain esters as for previously presented geranyl long-chain esters.

Open Access This article is distributed under the terms of the Creative Commons Attribution License which permits any use, distribution, and reproduction in any medium, provided the original author(s) and the source are credited.

\section{References}

1. Escalante J, Carrillo-Morales M, Linzaga I. Michael additions of amines to methyl acrylates promoted by microwave irradiation. Molecules. 2008;13:340-7.

2. Lidström P, Tierney J, Wathey B, Westman J. Microwave assisted organic synthesis. Tetrahedron. 2001;57:9225-83.

3. Garg N, Larhed M, Hallberg A. Heck arylation of 1,2-cyclohexanedione and 2-ethoxy-2-cyclohexenone. J Org Chem. 1998;63:4158-62.

4. Mallakpour SE, Hajipour AR, Khoee S. Polymerization of 4,4((hexafluoroisopropylidene)-N, N'-bis(phthaloyl-L-leucine) diacid chloride with aromatic diamines by microwave irradiation. J Polym Sci Polym Chem Ed. 2000;38:1154-60.

5. Mallakpour SE, Hajipour AR, Faghihi Kh. Microwave-assisted synthesis of optically active poly(amide-imide)s with benzophenone and L-alanine linkages. Eur Polym J. 2001;37:119-24.

6. Mallakpour SE, Hajipour AR, Faghihi Kh. Synthesis of novel optically active poly(ester-imide)s with benzophenone linkages by microwave-assisted polycondensation. Polym Int. 2000;49:1383-8.

7. Loupy A. Microwave in organic synthesis. Germany: Wiley; 2006.

8. Leadbeater NE. Microwave heating as a tool for sustainable chemistry. USA: CRC Press; 2011.

9. Larhed M, Olofsson K. Microwave methods in organic synthesis. Germany: Springer; 2006.

10. Perreux L, Loupy A. A tentative rationalization of microwave effects in organic synthesis according to the reaction medium, and mechanistic considerations. Tetrahedron. 2001;57:9199-223.

11. Wisniak J, Benajahu H. Sulfur bromination of jojoba oil. Ind Eng Chem Prod Res Dev. 1978;17:335-42.

12. Masayuki T. Jojoba wax in cosmetic creams and lotions. Cosmet Toiletries. 1980;95:39.

13. Gildemeister E, Hoffmann FR. The volatile oils. New York: Wiley; 1913.

14. Croteau R. Fragrance and flavor substances. Pattensen: D\&PS Verlag; 1980.

15. da Silva JCT, Gondim AD, Galvão LPFC, da Costa Evangelista JP, Araujo AS, Fernandes Jr VJ. Thermal stability evaluation of biodiesel derived from sunflower oil obtained through heterogeneous catalysis $\left(\mathrm{KNO}_{3} / \mathrm{Al}_{2} \mathrm{O}_{3}\right)$ by thermogravimetry. $\mathrm{J}$ Therm Anal Calorim. 2014;. doi:10.1007/s10973-014-4145-0.
16. Hong SG, Hsu HW, Ye MT. Thermal properties and applications of low molecular weight polyhydroxybutyrate. J Therm Anal Calorim. 2013;111:1243-50.

17. Satge C, Verneuil P, Branland R, Granet P, Krausz J, Rozier J, et al. Rapid homogeneous esterification of cellulose induced microwave irradiation. Carbohyd Polym. 2002;49:373-6.

18. Lewandowicz G, Fornal J, Walkowski A, Maczyński M, Urbaniak G, Szymańska G. Starch esters obtained by micro-wave radiation-structure and functionality. Ind Crop Prod. 2000;11:249-57.

19. Antova G, Vasvasova P, Zlatanov M. Studies upon the synthesis of cellulose stearate under microwave heating. Carbohydr Polym. 2004;57:131-4.

20. Gülsen Ö, Bahattin G, Osman A. Synthesis of esters under microwave irradiation using heteropoly acids as catalysts. Catal Lett. 2002;82:233-5.

21. Shieh WCh, Dell S, Repić O. Large scale microwave-accelerated esterification of carboxylic acids with dimethyl carbonate. Tetrahedron Lett. 2002;43:5607-9.

22. Loupy A, Pigeon P, Ramdani M. Synthesis of long chain aromatic esters in a solvent-free procedure under microwave. Tetrahedron. 1996;52:6705-12.

23. Hirose T, Kopek BG, Wang ZH, Yusa R, Baldwin BW. Microwave oven synthesis of esters promoted by imidazole. Tetrahedron Lett. 2002;44:1831-3.

24. Escalante J, Diaz-Coutino FD. Synthesis of $\gamma$-nitro aliphatic methyl esters via Michael additions promoted by microwave irradiation. Molecules. 2009;14:1595-604.

25. Bauer K, Garbe D, Surburg H. Common fragrance and flavor materials: preparation, properties and uses. New York: Wiley; 2001.

26. Worzakowska M, Ścigalski P. TG/DSC/FTIR characterization of linear geranyl diesters. J Therm Anal Calorim. 2013;113:56-60.

27. Worzakowska M, Ścigalski P. Synthesis and thermal behavior of linear neryl diesters in inert and oxidative atmosphere. J Therm Anal Calorim. 2014;115:783-92.

28. Worzakowska M. Thermal properties of citronelly diesters. J Therm Anal Calorim. 2014;118:299-309.

29. Worzakowska M. Synthesis, characterization and thermal properties of new flavor compounds. $\mathrm{J}$ Therm Anal Calorim. 2014;116:727-36.

30. Worzakowska M. TG/FTIR/QMS studies on long chain esters of geraniol. J Anal Appl Pyrolysis. 2014;. doi:10.1016/j.jaap.2014. 09.002 .

31. Sokrates G. Infrared and raman characteristic group frequencies, tables and charts. New York: Wiley; 2001.

32. Bilger EM, Hibbert H. Mechanism of organic reactions. IV. Pyrolysis of esters and acetals. J Am Chem Soc. 1936;58:823-6.

33. March J. Advanced organic chemistry: reactions, mechanisms and structure. New york: Wiley; 1992.

34. Zapata B, Balmaseda J, Fregoso-Israel E, Torres-Garcia E. Thermo-kinetics study of orange peel in air. J Therm Anal Calorim. 2009;98:309-15.

35. Ledeti I, Vlase G, Vlase T, Doca N, Bercean V, Fulias A. Thermal decomposition, kinetic study and evolved gas analysis of 1,3,5-triazine-2,4,6-triamine. J Therm Anal Calorim. 2014;118:1057-63.

36. Cheng H, Li K, Liu Q, Zhang S, Li X, Frost RL. Insight into the thermal decomposition of kaolinite intercalated with potassium acetate: an evolved gas analysis. J Therm Anal Calorim. 2014;117:1231-9.

37. Silva ACM, Gálico DA, Guerra RB, Perpétuo GL, Legendre AO, Rinaldo D, Bannach G. Thermal stability and thermal decomposition of the antihypertensive drug amlodipine besylate. J Therm Anal Calorim. 2014;. doi:10.1007/s10973-014-3992-z. 